\title{
Radix Scrophulariae Aqueous Extract Seems to Exert Neuroprotective Effects on Cerebral Ischemia and Reperfusion Injury with Inhibiting Apoptosis via ERK1/2 and p-38 MAPK Pathway
}

\author{
Weijie Xie ${ }^{1,2,3,4}$, Ping Zhou ${ }^{1,2,3,4}$, Xuelian Zhang ${ }^{1,2,3,4}$, Chenyang Zhang ${ }^{1,2,3,4}$, Xiangbao Meng ${ }^{1,2,3,4}$, \\ Guibo Sun $1,2,3,4 *$, and Xiaobo Sun $1,2,3,4 *$
}

1 Beijing Key Laboratory of Innovative Drug Discovery of Traditional Chinese Medicine (Natural Medicine) and Translational Medicine, Institute of Medicinal Plant Development, Peking Union Medical College and Chinese Academy of Medical Sciences, Beijing 100193, China; ginseng123@163.com (W. X.); zhoup0520@163.com (P. Z.); xIZhang2022@163.com (X. Z.); xwjginseng@126.com (C. Z.); xbmeng@implad.ac.cn (X.M.)

2 Key Laboratory of Bioactive Substances and Resource Utilization of Chinese Herbal Medicine, Ministry of Education, Beijing 100193, China

3 Key Laboratory of Efficacy Evaluation of Chinese Medicine against Glycolipid Metabolic Disorders, State Administration of Traditional Chinese Medicine, Beijing 100193, China

4 Zhongguancun Open Laboratory of the Research and Development of Natural Medicine and Health Products, Beijing 100193, China

* Correspondence: sunguibopaper@163.com (G.S.); sunxiaobopaper@163.com (X.S.); Tel.: +8610-5783-3220 (G.S.); +86-10-5783-3013 (X.S.)

\begin{abstract}
Ischemia stroke is one of a clinically common cerebrovascular disease. And Inhibition of brain tissue ischemia and reperfusion-induced damage, especially apoptosis, has an irreplaceable protective effect on ischemic nerves, and has special significance for the treatment of patients after treatment. However, the development of neuroprotective drugs still has certain challenges. Radix scrophulariae as a valuable medicine, has been discovered to has neuroprotective effects. Our researches initially proved that Radix scrophulariae aqueous extract (RSAE) exerting a neuroprotective effects on cerebral ischemia and reperfusion (I/R) injury in oxygen glucose deprivation and reperfusion (OGD/R)-induced $\mathrm{PC} 12$ cells and middle cerebral artery occlusion/reperfusion (MCAO/R) model mice, were associated with attenuation of infarct volume, brain water content, nitric oxide (NO) and malondialdehyde (MDA), inhibiting I/R-induced damage by reducing the levels of $L D H$ release, improving anti-oxidant capacity by upregulating the SOD, GSH-Px and CAT activity, stabilizing mitochondrial membrane potential, reducing neuronal apoptosis, necrosis and neuronal loss by regulating the expression of anti-apoptotic BCL-2and proapoptotic protein Bax, and elucidating downregulate the phosphorylation levels of MAPK pathways. Our findings may elaborate the neuroprotective effects and potential mechanisms of RSAE on focal cerebral I/R injury in mice. Since, Radix scrophulariae, as a potential neuroprotective natural plant, has originally been identified to, our results may offer directions and clues for discovering new active compounds or drugs for treatment of ischemic stroke, which allows us to discover many new natural active chemicals by chemical separation and identification, and provide new insights into therapeutic targets in stroke patients.
\end{abstract}


Keywords: Radix scrophulariae; ischemia stroke; cerebral ischemia and reperfusion; apoptosis; ERK1/2 MAPK; p-38 MAPK

\section{Instruction}

Ischemia stroke is one of a clinically common cerebrovascular disease, accounting for $70 \%$ to $80 \%$ of all cerebrovascular patients, and about 15 million of people worldwide suffer from stroke each year, resulting in approximate 5 million deaths, which is a primary cause of disability and death worldwide $[1,2]$. So far, the primary principle of clinical treatment on ischemic stroke is to restore blood and oxygen supply or make reperfusion with blood in the ischemic brain tissue as soon as possible. However, re-opening the occluded cerebral vessels, often produce the pathological damage in the ischemic tissue and make cerebral ischemia and reperfusion injury even further aggravated or irreversible, which is called cerebral ischemia-reperfusion [2, 3]. In order to explore better treatment for ischemic stroke and reperfusion injury, researchers have carried out extensive and in-depth research on its pathogenesis and proposed a series of theories [4,5], mainly including energy metabolism disorders, oxidative stress, Glutamate toxicity, $\mathrm{Ca}^{2+}$ overload, excessive NO synthesis, apoptosis, etc., meanwhile developing a series of new drugs [5], such recombinant tissue plasminogen activator ( $r$-TPA), aspirin and heparin. At present, some significant progress has been made to alleviate the huge public health problems of stroke, great preventive efforts have been made to reduce the morbidity and mortality of strokes, and special intensive care units have been established to improve the functional consequence of stroke patients, but the management of acute ischemic stroke has not made significant strides since the introduction of recombinant tissue plasminogen activator (r-TPA) two decades ago [3], and it is regarded as the only thrombolytic agent approved by the US Food and Drug Administration for stroke treatment and available for stroke treatment [6]. However, since the time window is narrow, this treatment is only suitable for a limited stroke patients (<10\%) [7].

After cerebral ischemia, especially after in the cerebral ischemia and reperfusion process, various damage factors exist, including oxygen free radicals oxidative stress, Glutamate toxicity, $\mathrm{Ca}^{2+}$ overload, excessive nitric oxide (NO) synthesis, apoptosis are produced through various pathways, such as hydroxyl radicals and superoxide anions. In the pathogenesis and treatment of acute ischemic stroke, brain oxygen cells can damage brain cells due to damage or inhibition of the body's oxidative defense, leading to neuronal apoptosis, necrosis or loss in the hippocampus and cortex of the brain [8-13]. Therefore, the research and development of neuroprotective drugs to reduce apoptosis and necrosis of brain tissue for the treatment of acute ischemic stroke is clinically significant [14].

Apoptosis is involved in the pathogenesis and pathological mechanism of ischemic stroke, called as programmed cell death. It is widely found in the life activation development and physiological cell turnover during development and physiological cell turnover and pathological damage and environmental stimulation leading to disorders, such as stroke [12, 14-17]. Furthermore, arsenic-induced cytotoxicity and oxidative stress damage could lead to a variety of apoptosis, in a variety of cell types, including neuronal cells, myoblasts, osteoblasts, etc, which are closely related to the activation of PI3K-Akt/mTOR, mitogen-activated protein kinases (MAPKs) and endoplasmic reticulum (ER) ) Stress regulatory signaling pathways, [3, 4, 8-10]. While the mechanism of neuronal apoptosis during cerebral ischemia is not yet completely elucidated, many 
evidences have shown that neuronal apoptosis and cell cycle regulation. And the gen-activated protein kinase (MAPK) signaling pathway, including $E R K_{1 / 2}, J_{N K_{1 / 2}}$ and $p-38[8-10,13]$, may inhibit the activation and hyper-proliferation of glial cells by regulating the cell cycle, reducing the harmful factors that secrete damaged neurons; on the other hand, it reduce glial proliferation and swelling caused by local microcirculatory disorders, which creates a favorable environment for survival on neuronal apoptosis [18]. The MAPK signaling pathway has been implicated in the regulation of cytokine expression and cell apoptosis after stroke, and it might represent a novel therapeutic target $[19,20]$. Thus, the studies of MAPK activation in ischemic brain may provide fertile ground for the discovery of novel therapeutic agents for stroke patients.

In China, traditional Chinese herbal medicines and combination preparations are used to treat cerebrovascular diseases, which can be traced back to the Han Dynasty. Even thousands of years ago, the medical formulary recorded many valuable Chinese medicines and classic prescriptions for the treatment of brain I/R related diseases, such as melon, salvia, mulberry, panax notoginseng, ganoderma lucidum [21]. Nowadays, several new compound TCM preparations have been formulated for the treatment of cerebrovascular diseases in China [15, 16, 21]. Radix scrophulariae called Xuan Shen in Chinese, a traditional Chinese medicine, is derived from the dried roots of Scrophularia ningpoensis Hemsl. Owing to its excellent traditional therapeutic effects, including blood cooling, yin nourishing, fire purging, and toxin removing, Radix scrophulariae has been used for thousands of years in China [22, 23]. Modern pharmacological studies and clinical practice demonstrated that it possess anti-angiogenesis, ventricular remodeling, anti-inflammatory, and antimicrobial activities [21, 22, 24]. And some studies demonstrated the Radix scrophulariae extract have effects of anti-apoptotic and anti-inflammatory through potentially affecting the mitogen-activated protein kinases (MAPKs) Signaling pathway and inhibition of the NF-KB pathway [24]. Although some pharmacological studies have been reported, the role and mechanism of Radix scrophulariae against cerebral ischemia has not been clearly elaborated, and the chemical basis of anti-cerebral ischemia is still unclear.

Based on above, we hypothesized that Radix scrophulariae may extract neuroprotective effects on cerebral ischemia and reperfusion injury with inhibiting oxidative stress damage and inhibiting apoptosis by regulating the MAPK pathway. Therefore, we investigated the effects of the Radix scrophulariae aqueous extract (RSAE) on PC 12 cells suffered with the oxygen glucose deprivation and reperfusion (OGD/R) model and MCAO/R mice in focal cerebral ischemia. And a total of thirty-six compounds were identified from RSAE based on the accurate mass measurement of precursor and product ions via MS/MS-Q-TOF, as previously described [22, 23]. 


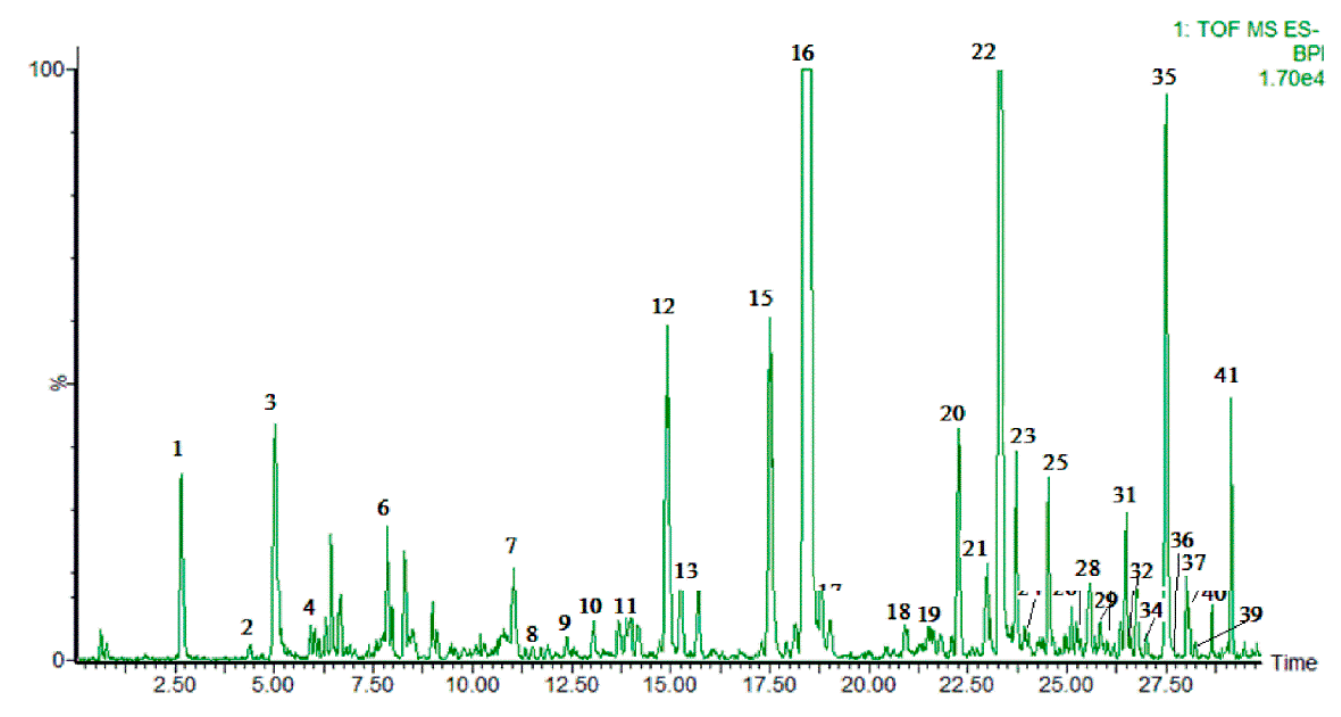

Figure 1 TIC of Radix scrophulariae aqueous extract in the negative ion mode via UPLC-Q-TOF-MS

\section{Result}

\subsection{Effects of RSAE on cell viability in PC12 cell after OGD/R}

Neuronal viability of PC12 pheochromocytoma cells, was assessed by both the MTT assay and we evaluated cell damage by measuring the amount of extracellular LDH release. As shown in Figure 2 , the $2 \mathrm{~h}$ of OGD and following $24 \mathrm{~h}$ of reperfusion made cell viability of PC12 cells significantly decrease $(P<0.0001$,$) and the level of L D H$ release was remarkably increased $(P<0.0001$, Figure $3 A)$. By contrast, incubation of cells with different concentrations of Radix scrophulariae aqueous extract (RSAE: 5.0, 12.5, 25.0 and $50.0 \mu \mathrm{g} / \mathrm{mL}$ ) alone for $4 \mathrm{~h}$ did not affect cell viability (Figure 2A). And pretreatment of PC12 cells with different concentrations of RSAE for $24 \mathrm{~h}$, significantly increased the cell viability from $60.11 \%$ to $66.86 \%, 69.07 \%, 92.42 \%, 83.21 \%(P<0.0001$, Figure $2 D)$ in a dose-dependent manner. Furthermore, the $12.5 \mu \mathrm{g} / \mathrm{mL}$ of RSAE had much better effect on improving cell viability than the other doses. So the concentration, $12.5 \mu \mathrm{g} / \mathrm{mL}$ of RSAE, was used in subsequent experiments. 
(A)

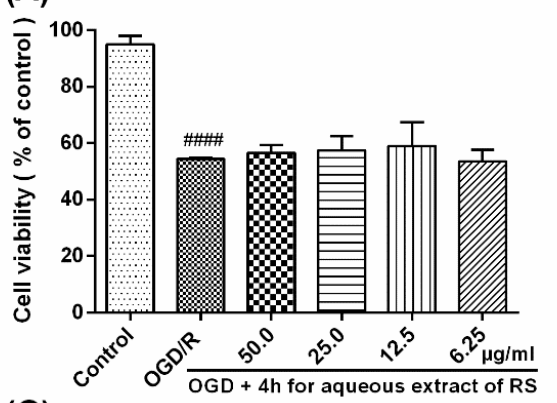

(C)

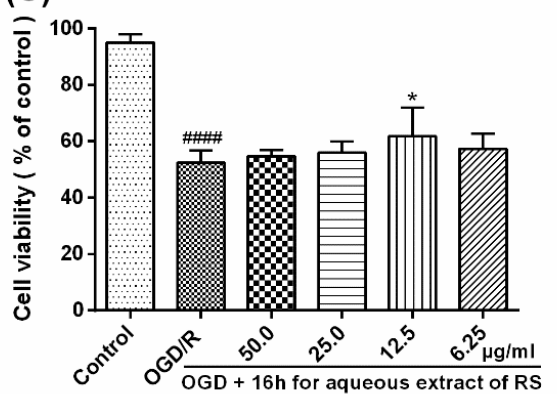

(B)

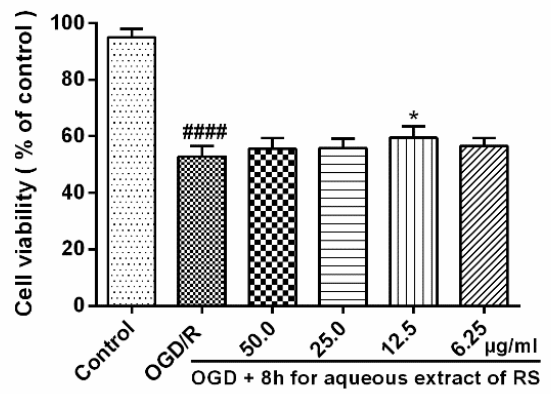

(D)

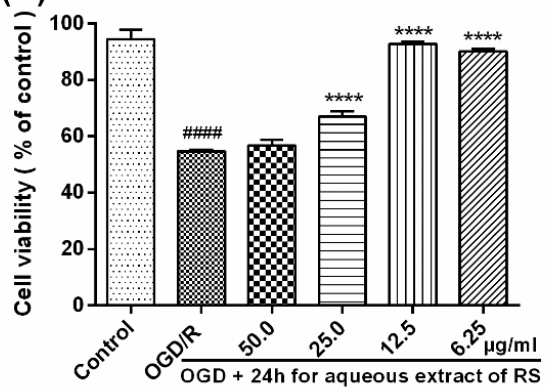

Figure 2 Effects of Radix scrophulariae aqueous extract on cell viability in PC12 cells after OGD/R. After PC12 cells were exposed to $2 \mathrm{~h}$ of OGD following $24 \mathrm{~h}$ of reperfusion, cell viability was significantly decreased; (A) Incubation of PC12 cells with different concentrations of $\operatorname{RSAE}(5.0,12.5,25.0$ and $50.0 \mu \mathrm{g} / \mathrm{mL})$ alone for $4 \mathrm{~h}$ did not affect cell viability. (B) (C) Pretreatment with $\mathrm{RSAE}(12.5 \mu \mathrm{g} / \mathrm{mL})$ for $8 \mathrm{~h}$ and $16 \mathrm{~h}$ significantly improved the cell viability. (D) After PC12 cells were exposed to $2 \mathrm{~h}$ of OGD following $24 \mathrm{~h}$ of reperfusion, pretreatment with $\operatorname{RSAE}(5.0,12.5,25.0$ and $50.0 \mu \mathrm{g} / \mathrm{mL})$ for $24 \mathrm{~h}$ significantly improved the cell viability. Mean values \pm standard error of the mean $(\mathrm{n}=6) ; \mathrm{P}<0.05, * * \mathrm{P}<0.01, * * * * \mathrm{P}<0.00001$ versus $\mathrm{OGD} / \mathrm{R}$ group; $\# \mathrm{P}<0.05, \# \# \mathrm{P}<0.01, \# \# \# \mathrm{P}<0.0001$ versus control group.

\subsection{Effects of RASE on the levels of LDH, MDA and oxidative stress in PC12 cells after OGD/R}

As shown in Fig.3, after PC12 cells were exposed to the oxygen glucose deprivation /reperfusion (OGD/R) treatment, compared with control groups, the level of $L D H$ release remarkably increased $(P<0.0001$, Figure $3 A)$, but the levels of $L D H$ release were markedly reduce by $12.5 \mu \mathrm{g} / \mathrm{mL}$ of Radix scrophulariae aqueous extract (RSAE) from $6.05 \pm 0.16$ to $4.8 \pm 0.26$ ( $P<0.0001$, Figure $3 A$ ).

And compared with control group, $\mathrm{OGD} / \mathrm{R}$ treatment markedly increased the concentration of MDA from 25. $84 \pm 7.09$ to $64.81 \pm 2.23$ and NO from $8.36 \pm 2.75$ to $19.79 \pm 6.71$ ( $P<0.001$, Figure $3 B$ and $C$ ). But $12.5 \mu \mathrm{g} / \mathrm{mL}$ of RSAE inhibited the $O G D / R$-induced damage and made concentration of MDA and NO decreased to $34.24 \pm 8.36$ and $10.24 \pm 3.52$ ( $P<0.001$, Figure $3 B$ and $C$ ).

In additions, after PC12 cells were exposed to OGD/R treatment, compared with control groups, the activity of SOD, CAT and GSH-Px remarkably decreased, as respectively presented in Fig.3D (from 17.60 \pm 1.03 to $11.79 \pm 2.25, P<0.01$ ), Fig.3E (from 32.71 \pm 2.29 to $16.39 \pm 8.20, P<0.001$ ) and Fig.3F (from $142.38 \pm 9.04$ to $43.05 \pm 16.46, \mathrm{P}<0.0001$ ). But $12.5 \mu \mathrm{g} / \mathrm{mL}$ of RSAE pretreatment significantly increased the SOD, GSH-Px and CAT activity in OGD/R-treated PC12 cells, as displayed in Fig.3D (from 11.79 \pm 2.25 to $16.40 \pm 2.96, P<0.05$ ), $E$ (from $16.39 \pm 8.20$ to $25.94 \pm 3.61, P<0.05$ ) and $F$ (from $43.05 \pm 16.46$ to $120.42 \pm 19.09, P<0.001$ ). 
(A)
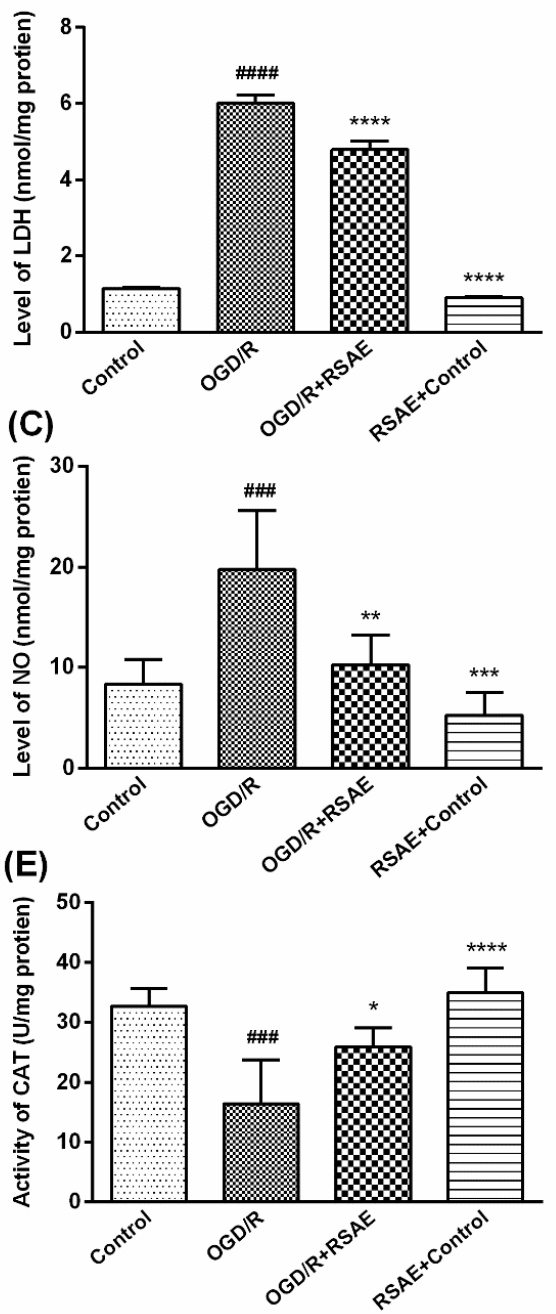

(B)
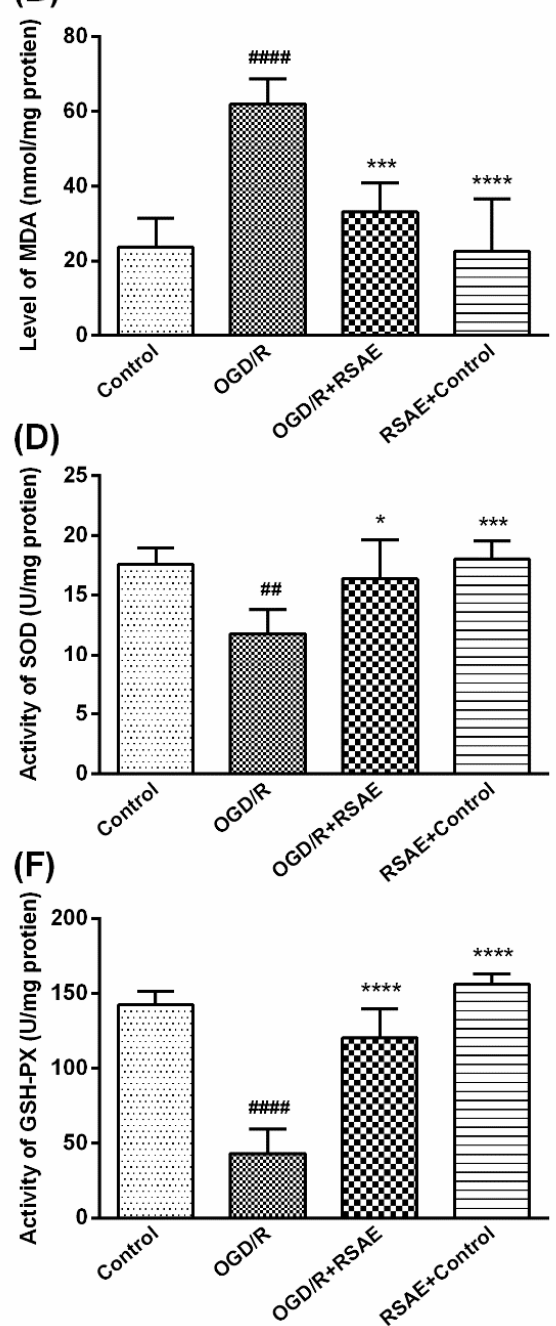

Figure 3 Effects of RASE on the levels of LDH, MDA and oxidative stress in PC12 cells after OGD/R. (A) (B) (C), $12.5 \mu \mathrm{g} / \mathrm{mL}$ of RSAE inhibited the OGD/R-induced damage and decreased the levels $n$ of LDH (A), MDA (B) and NO (C). Pretreatment with RSAE (12.5 $\mu \mathrm{g} / \mathrm{mL})$ for $24 \mathrm{~h}$ significantly improved SOD (D), CAT (E) and GSH-Px (F) activity. Mean values \pm standard error of the mean $(n=6) ; P<0.05,{ }^{* *} P<0.01$, **** $\mathrm{P}<0.0001$ versus $\mathrm{OGD} / \mathrm{R}$ group; \# $\mathrm{P}<0.05$, \#\# $\mathrm{P}<0.01$, \#\#\#\# $\mathrm{P}<0.0001$ versus control group.

\subsection{Effects of RASE on mitochondrial membrane potential in PC12 cells after OGD/R}

The reduction of mitochondrial membrane potential (MMP) is linked with OGD/R-induce apoptosis, and regarded as a vital event during apoptosis. So, JC-1 staining was used to detect the change in MMP. Fig. $4 \mathrm{~A}$ and $\mathrm{B}$ showed that, compared with the control group, $\mathrm{OGD} / \mathrm{R}$ markedly made the red fluorescence intensity weaken from $1.00 \pm 0.13$ to $0.52 \pm 0.043(P<0.001)$, while the green fluorescence intensity fluctuated slightly among these groups. However, $12.5 \mu \mathrm{g} / \mathrm{mL}$ of RSAE inhibited the OGD/R-induced reduction of MMP and made the red fluorescence increase to $1.02 \pm$ $0.05(P<0.001$, Figure $4 B$ ). And the ratio of red/green fluorescence intensity was greatly enhanced by RSAE from $0.52 \pm 0.043$ to $1.25 \pm 0.065(P<0.001$, Figure $4 C)$, which was consistent with the result of the red fluorescence. 


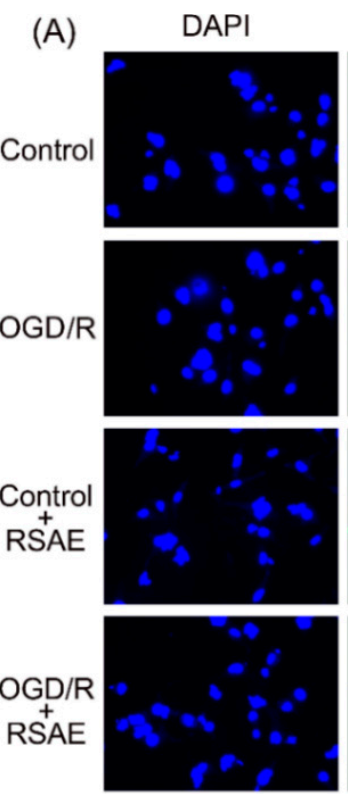

(B)

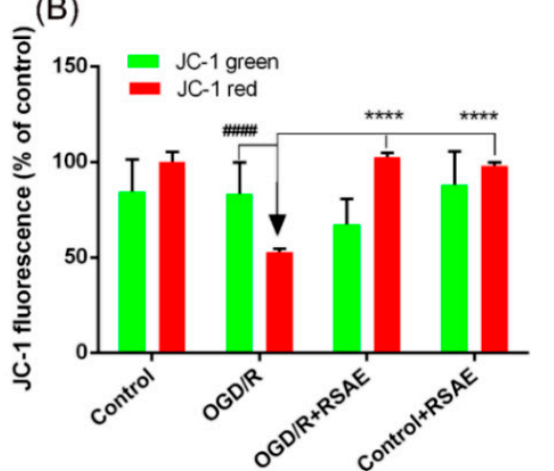

Green
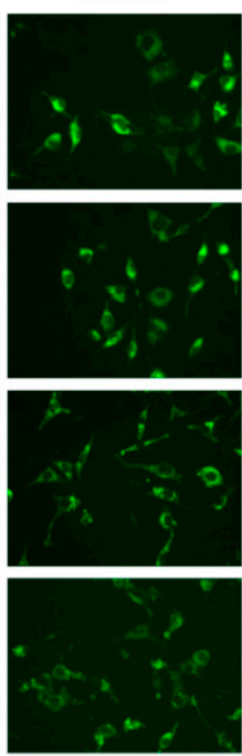

(C)
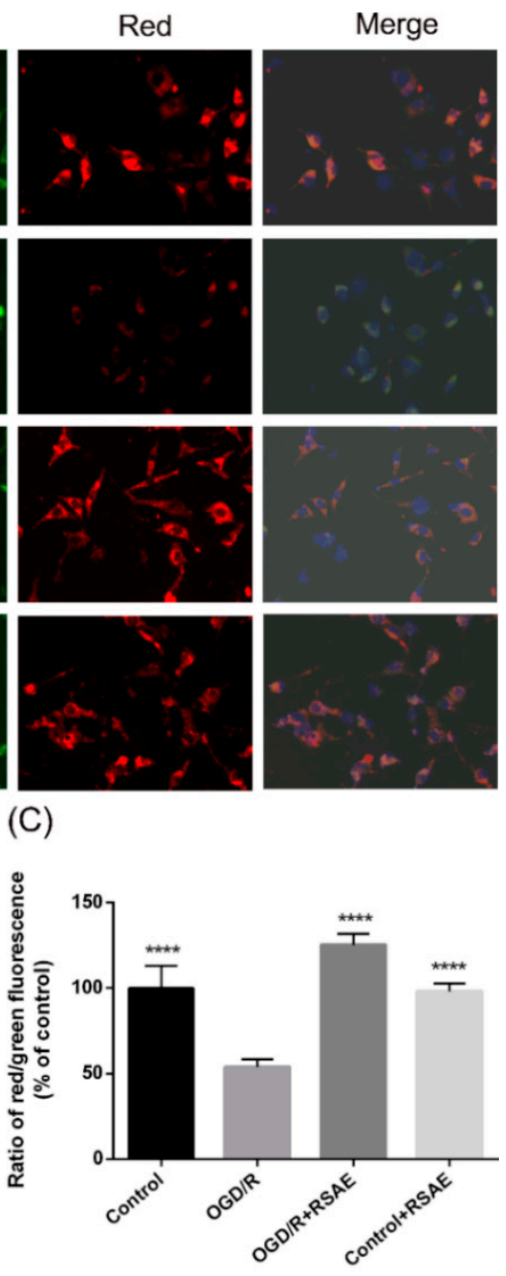

Figure 4 Effects of RASE on mitochondrial membrane potential in PC12 cells after OGD/R. Effects of RASE on MMP in PC12 cells after $\mathrm{OGD} / \mathrm{R}$. (A) (B) (C), $12.5 \mu \mathrm{g} / \mathrm{mL}$ of RSAE inhibited the OGD/R-induced reduction of MMP (A) (B) and made the ratio of red/green fluorescence intensity increase(D). Mean values \pm standard error of the mean $(n=6) ; P<0.05, * * P<0.01, * * * * P<0.0001$ versus $0 G D / R$ group; \# $\mathrm{P}<0.05$, \#\# $\mathrm{P}<0.01$, \#\#\#\# $\mathrm{P}<0.0001$ versus control group.

\subsection{Effects of RASE on infarct volume, brain water content, MDA, NO and SOD}

To assess the effects of RASE on focal brain ischemia injury, KM mice were subjected to $2 \mathrm{~h}$ of MCAO and $24 \mathrm{~h}$ of reperfusion. And the infarct volume of the ipsilateral brain was measured with TTC staining (Figure $5 A$ ). As shown in Figure $5 A$ and $5 B$, the MCAO/R operation significantly increased corrected infarct volume, compared the sham operation group $(P<0.0001$, Figure $5 A$ and 5B). But pretreated with RASE (2.4g $\mathrm{kg}^{-1}$ of the original drug) and $12 \mathrm{mg} \cdot \mathrm{kg}^{-1}$ of nimodipine for $7 \mathrm{~d}$, had made the corrected infarct volumes remarkably decrease in comparing to those in the $M C A O / R$ group ( $P<0.0001$, Figure $5 A$ and $5 B)$.

To evaluate the brain edema in ischemia brain region, we examined brain water content of all the groups. The results showed the brain water content (BWC) distinctly increased in ischemia brain hemisphere in the MCAO/R group, which was significantly reduced by RASE $\left(2.4 \mathrm{~g} \cdot \mathrm{kg}^{-1}\right.$ of the original drug) pretreatment $(P<0.0001$, Figure $5 C)$.

Moreover, compared with the sham-operated group, the MCAO/R operation obviously reduced the activity of SOD from $76.61 \pm 7.67$ to $44.38 \pm 5.91$ ( $P<0.01$, Figure $5 \mathrm{D}$ ) and respectively increased the concentration of MDA from $2.56 \pm 0.47$ to $4.43 \pm 0.99$ ( $P<0.01$, Figure $5 E$ ) and NO from 
$1.29 \pm 0.43$ to $2.37 \pm 0.40(P<0.01$, Figure $5 F)$. But pretreatment of RSAE inhibited the MCAO/Rinduced ischemic damage and made the activity of SOD increase to $69.63 \pm 7.14(P<0.01$, Figure $5 D)$, and the concentration of MDA and NO respectively decrease to $2.68 \pm 0.27$ and $1.54 \pm 0.69(P<0.01$, Figure 5E and F).
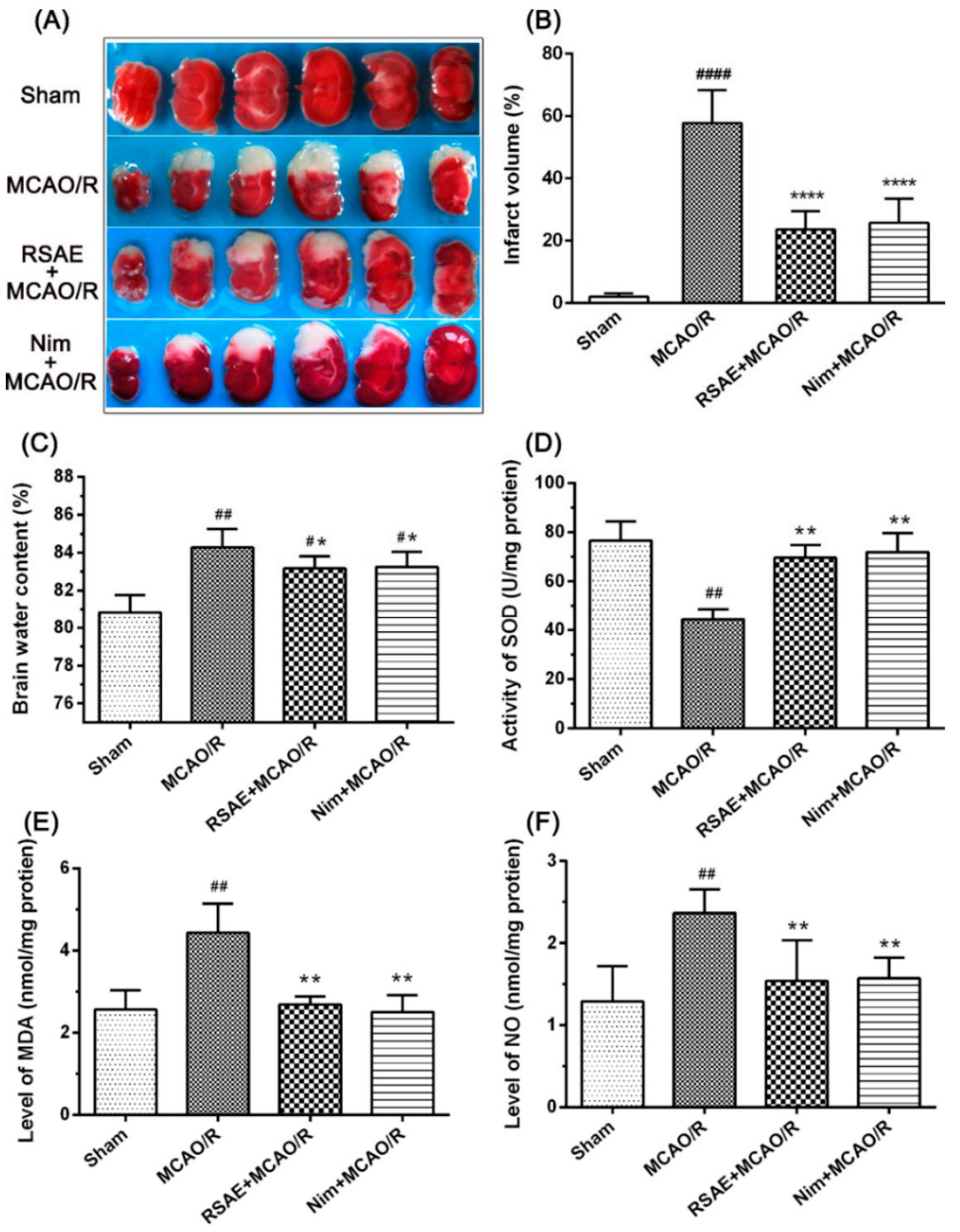

Figure 5. Effects of RASE on infarct volume, brain water content, MDA, NO and SOD in mice exposed to MCAO/R injury. RSAE reduced the infarct volume and brain water content (BWC). (A) Representative images of TTC-stained brain sections from the sham or RSAE-treated animals collected $24 \mathrm{~h}$ ater infarction. (B) Quantitative analysis of the infarct volume. (C) Brain water content in ischemia hemispheres of all the groups. (D) The activity of SOD in ischemia hemispheres of all the groups. (E) The level of MDA in ischemia hemispheres of all the groups. (F) The level of NO in ischemia hemispheres of all the groups. Mean values \pm standard error of the mean $(n=10) ; P<0.05, * * P<0.01$, **** $\mathrm{P}<0.0001$ versus MCAO/R group; \# $\mathrm{P}<0.05$, \#\# $\mathrm{P}<0.01$, \#\#\#\# $\mathrm{P}<0.0001$ versus Sham-operated group.

\subsection{Representative images of HE staining and Nissle staining}

Furthermore, the neuroprotective effects RSAE on cerebral ischemia and reperfusion leading to neurological damage and morphological changes was confirmed by Nissle staining and H\&E staining on sections from ischemic cortex at $24 \mathrm{~h}$ after ischemia/reperfusion in mice (Figure 6)

As shown in Figure 6A and Figure 6C, the nerve cells of the sham operation group presented 
normal structural form: the cell outline was clear and the structure was compact, and the nucleolus was clearly visible, which was similar to the non-ischemic brain tissue of the MCAO/R model group and the RSAE-treated group.

However, edema and necrosis were observed in the ischemic cortex and hippocampus of the $\mathrm{MCAO/R}$ group (Figure 6A); the gap around some neurons was enlarged, the nerve cells were sparse, the neurons were swollen or shrunk, the nucleolus disappeared, the nuclear membrane was dissolved, and the nucleus was solid. Compared with the model group, the ischemic changes of nerve cells were alleviated by RSAE pretreatment; only some nerve cells were degenerated and necrotic; the cell body deformation was reduced, and the number of viable cells was more than that of the model group.

Compared with the sham operation group, after focal cerebral ischemia, the ischemic cortex neuron density significantly descended from $49.93 \pm 8.71$ to $7.87 \pm 4.27(P<0.001$, Figure $6 B)$, and the focal cerebral ischemia (MCAO/R) operation significantly made ischemic neuron density in CA1 region of hippocampus decline from $73.38 \pm 8.51$ to $42.13 \pm 16.21$ ( $P<0.01$, Figure 6D). But RSAE pretreatment (2.4 g. $\mathrm{kg}^{-1}$ of the original drug) substantially reduced neuronal damage from MCAO/R and made the ischemic cortex neuron density significantly ascend to 21.70 $\pm 9.57(P<0.01$, Figure $6 \mathrm{~B})$ and the ischemic neuron density in hippocampus CA1 region significantly rise to $61.90 \pm 4.75$ $(P<0.01$, Figure 6D).

(A)

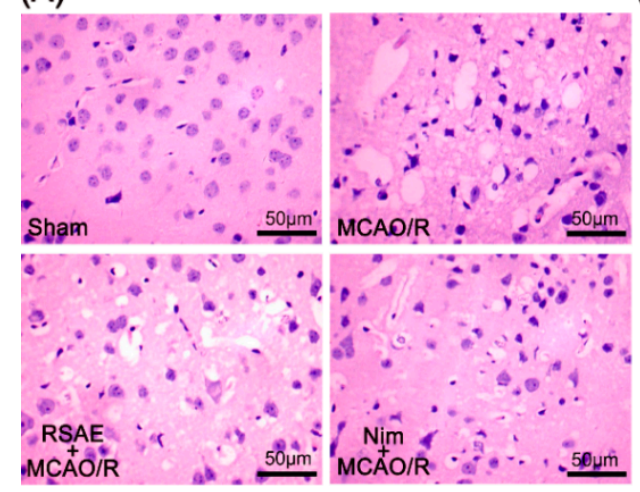

(B)

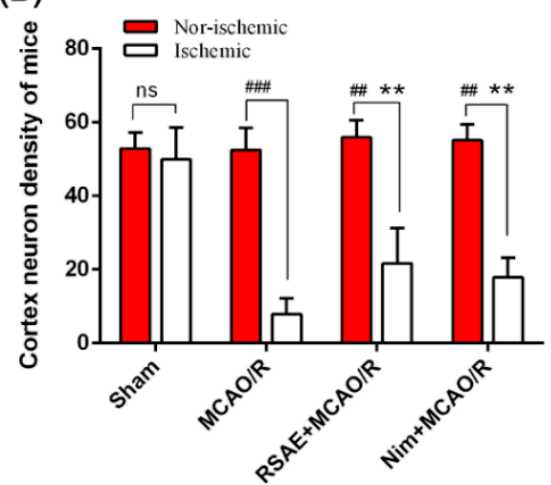

(C)

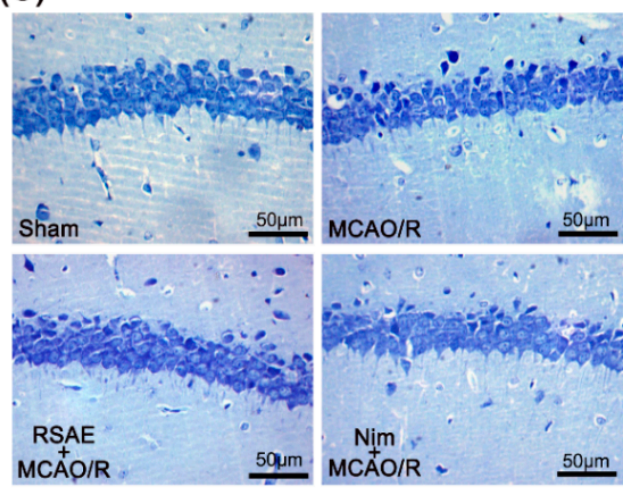

(D)

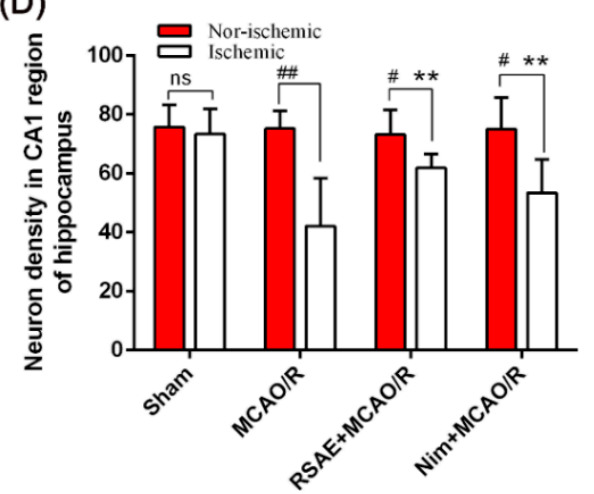

Figure 6 Representative images of HE staining and Nissle staining performed on sections from ischemic brain at $24 \mathrm{~h}$ after ischemia/reperfusion in mice. (A) Representative H\&E staining in the cortex at $24 \mathrm{~h}$ after ischemia/reperfusion. (B) The ischemic and norischemic cortex neuron density of mice after focal cerebral ischemia. (C) Representative Nissle staining in the cortex at $24 \mathrm{~h}$ after ischemia/reperfusion. (D) The neuron density in CA1 region of hippocampus of mice after focal cerebral ischemia. Mean values \pm standard error of the mean $(\mathrm{n}=10)$; $\mathrm{P}<0.05, * * \mathrm{P}<0.01, * * * * \mathrm{P}<0.0001$ versus MCAO/R group; \# $\mathrm{P}<0.05, \# \# \mathrm{P}<0.01, \# \# \# \mathrm{P}<0.0001$ versus Shamoperated group. Scale bar, $50 \mu \mathrm{m}$. 


\subsection{Effects of RSAE on the number of Bax and Bcl-2 positive cells in mice with focal cerebral ischemia}

To further investigate the effects of RSAE on MCAO/R-induced brain tissue apoptosis, immunohistochemistry was used to detect the Bax (pro-apoptotic protein) and the BCL-2 (antiapoptotic protein) expression level in the ischemic and non-ischemic cortex and hippocampus region. And it was judged that the positive cells were yellow in the cytoplasm or nucleus. Three

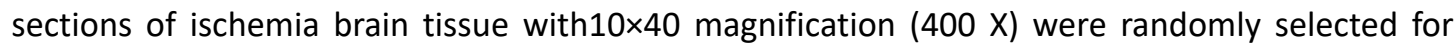
image analysis. As shown in Figure 7A and 7B, the positive expression of $\mathrm{Bax}$ and $\mathrm{Bcl}-2$ was characterized by deep staining of cytoplasm brown-yellow, concentrated around the infarct.

As displayed in figure 7D, compared to the sham group, the ratio of Bax positive cells in the ischemic peripheral area of the middle cerebral artery occlusion/reperfusion (MCAO/R) model group was significantly added from $54.47 \pm 4.34$ to $68.93 \pm 8.54$ after focal cerebral ischemia in the mice $(P<0.01)$. But, compared with the model group, the expression of $B a x$ in the ischemic peripheral area was significantly reduced to $61.63 \pm 9.10$ by RSAE pretreatment $\left(2.4 \mathrm{~g} \cdot \mathrm{kg}^{-1}\right.$ of the original drug) ( $\mathrm{P}<0.01$, Figure $7 \mathrm{C}$ ). In contrast, Bcl-2 expression (ratio of $\mathrm{Bcl}-2$ positive cells) in the MCAO/R model group significantly descended from $68.73 \pm 1.95$ to $37.30 \pm 3.15$, compared to the control group ( $\mathrm{P}<0.001$, Figure $7 \mathrm{D})$. And RSAE significantly improved the ratio of $\mathrm{Bcl}-2$ positive cells to $83.87 \pm 2.05$, compared to the MCAO/R model group $(P<0.0001$, Figure $7 D)$. Moreover, the ratio of Bax and Bcl-2 positive cells presented no significant different between the ischemic and norischemic brain neuron sections of mice after focal cerebral ischemia, excluding the MCAO/R model group.

(A)

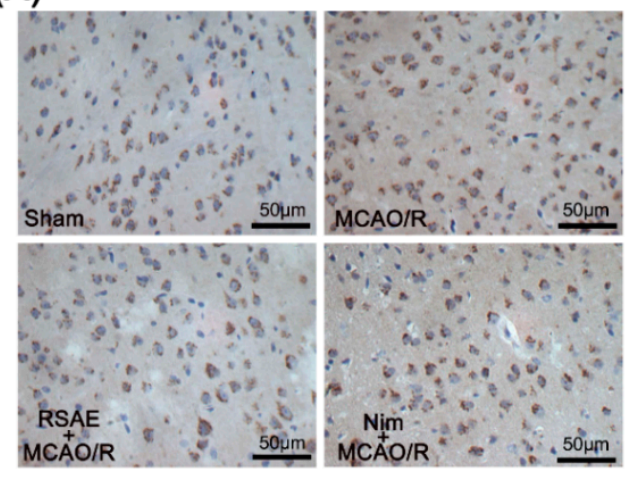

(C)

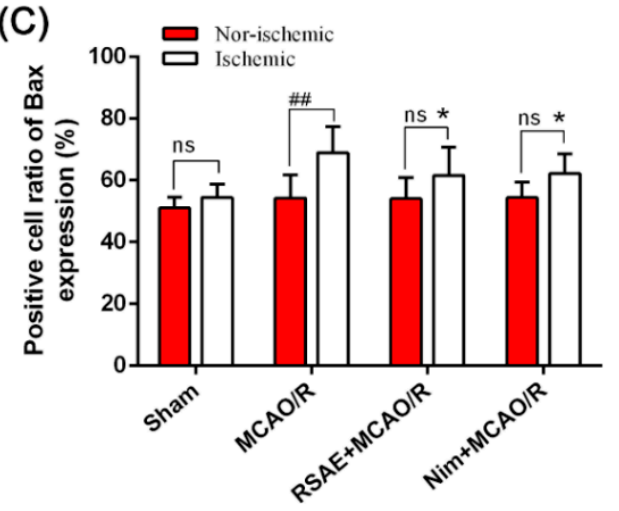

(B)

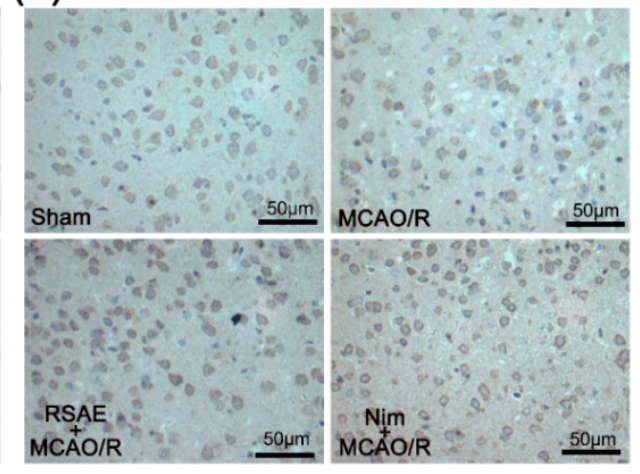

(D)

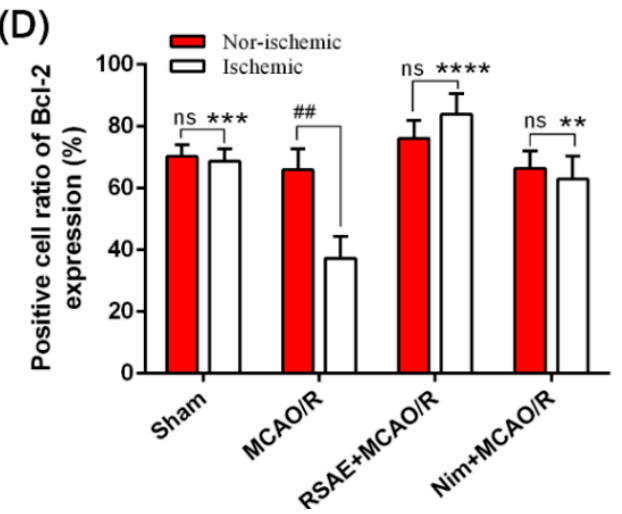

Figure 7 Effect of RSAE on the levels of Bax and Bcl-2 positive cells in mice with focal cerebral ischemia at $24 \mathrm{~h}$ after ischemia/reperfusion in mice. (A) Representative immunohistochemical staining images of pro-apoptotic Bax in the ischemic and nor- 
ischemic neuron sections at $24 \mathrm{~h}$ after ischemia/reperfusion. (B) Representative immunohistochemical staining images of anti-apoptotic $\mathrm{BAX}$ in the ischemic and nor-ischemic neuron sections at $24 \mathrm{~h}$ after ischemia/reperfusion. (C) Quantitative analysis of Bax positive cells in mice with focal cerebral ischemia at $24 \mathrm{~h}$ after ischemia/reperfusion. (D) Quantitative analysis of Bcl-2 positive cells in mice with focal cerebral ischemia at $24 \mathrm{~h}$ after ischemia/reperfusion. Mean values \pm standard error of the mean $(\mathrm{n}=10) ; \mathrm{P}<0.05, * * P<0.01, * * * * P<0.0001$ versus MCAO/R group; \# P<0.05, \#\# $\mathrm{P}<0.01$, \#\#\# $\mathrm{P}<0.0001$ versus Sham-operated group. Scale bar, $50 \mu \mathrm{m}$.

\subsection{Effects of RSAE on the levels of ERK1/2, JNK1/2 and p38 MAPK in mice after MCAO/R}

It is known that the activation of MAPKs signaling pathways plays a critical role against a variety of OGD/R and MCAO/R-induced apoptotic, and could regulate the phosphorylation of ERK1/2 JNK1/2 and p38 MAPK to exert Neuroprotective Effects [8-11, 13, 25-27]. Base on the Effects of RASE on the oxidative stress in OGD/R and MCAO/R model, therefore, the association between oxidative stress damage induced by OGD/R and MCAO/R model and the subsequent activation of the MAPK was elucidated.

As shown in Figure $8 A$ and $B$, the protein ERK1/2 and its phosphorylation levels of ERK ( $p$-ERK) in mice with focal cerebral ischemia were significantly increased by MCAO/R model (respectively, $\mathrm{P}<0.01, \mathrm{P}<0.05$ ). Comparatively, pre-treatment with RSAE reduced the phosphorylation levels of ERK ( $p$-ERK), and had no significant difference on the protein ERK1/2, indicating that RSAE may regulate the phosphorylation levels of ERK to produce cerebral anti-ischemic effect. Similarly, the increasement of the phosphorylation levels of P38 induced by MCAO/R was strikingly abrogated by pretreatment with RSAE $(P<0.01$, Figure $8 D$ and $F)$, indicating that RSAE also may regulate the phosphorylation levels of ERK to produce cerebral anti-ischemic effect. Moreover, RSAE showed no significant difference on the JNK1/2 and its phosphorylation levels. The results indicated that RSAE may play a key role against focal cerebral ischemia in mice via suppressing its phosphorylation levels of ERK1/2 and p38 MAPK. 


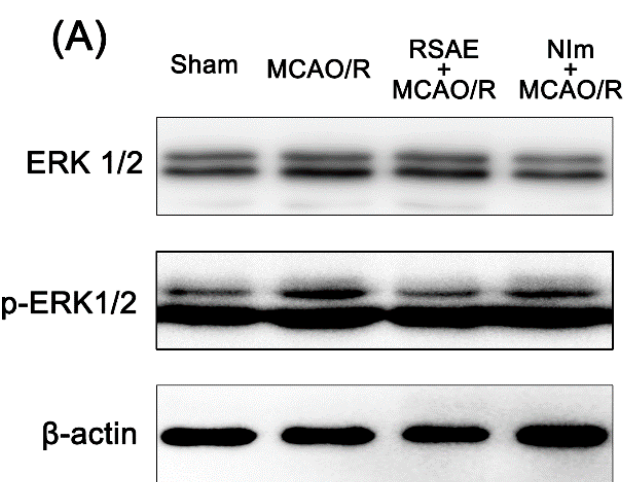

(B)
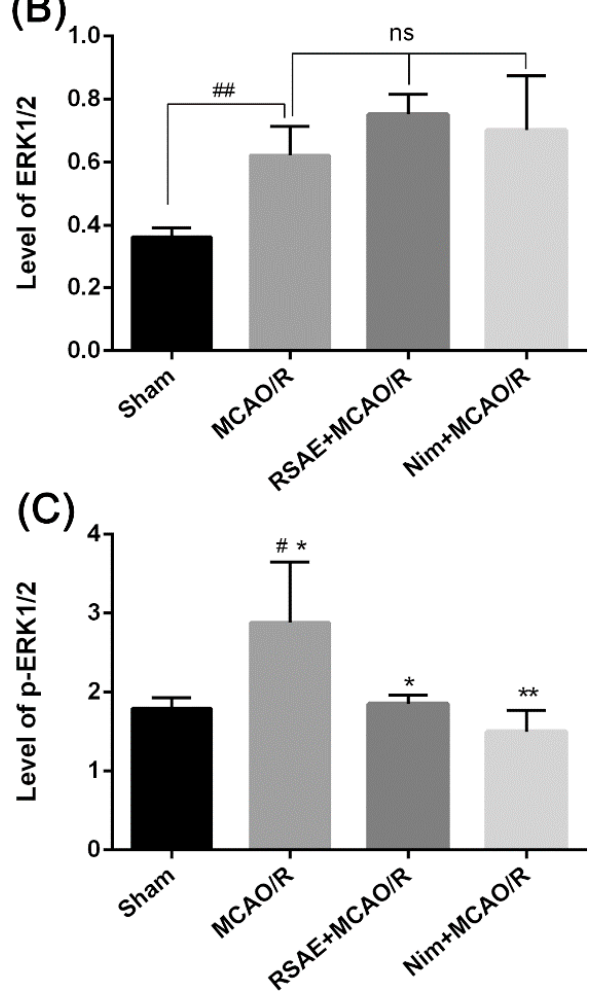

(D) Sham MCAO/R $\begin{gathered}\mathrm{RSAE} \\ \text { MCÁO/R }\end{gathered} \stackrel{\mathrm{MCA} O / \mathrm{N}}{\mathrm{NIm}}$

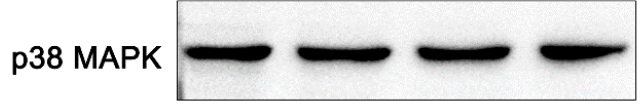

p-p38 MAPK
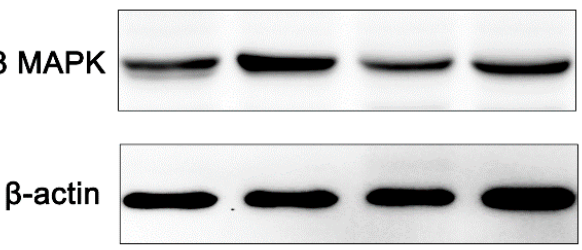

(E)
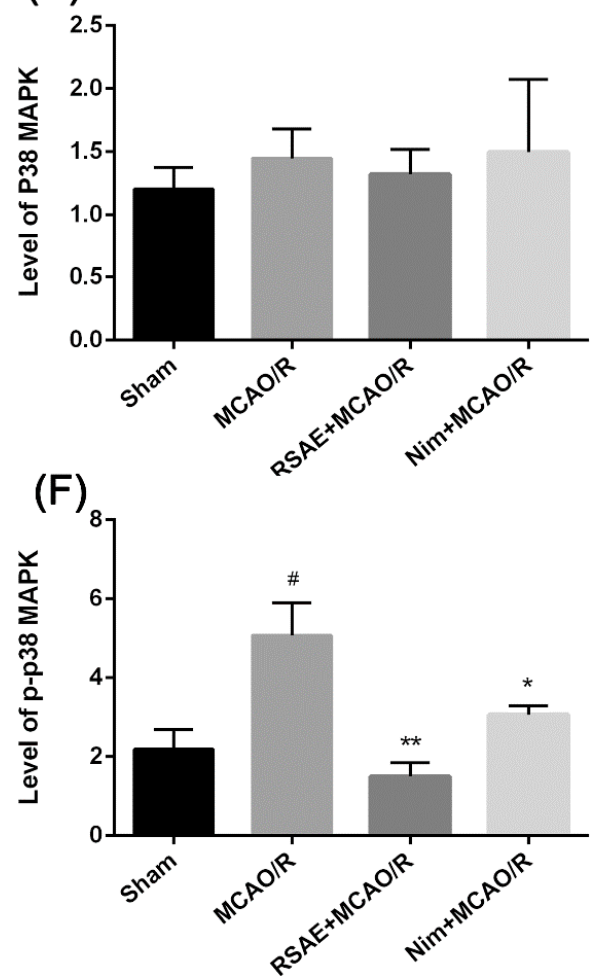

Figure 8 Effects of RSAE on the expression of phosphorylation of ERK1/2, JNK, and P38 in the hippocampus of ischemic brain sections. (A) (D), the protein levels of phospho-ERK, phospho-JNK, and phospho-P38 in the hippocampus of ischemic brain sections were examined by western blot analysis. (B)(C)(E)(F), the IOD value of ERK, P-ERK, P38 and p-P38 were quantified and analyzed using the Gel-Pro analyzer software. Mean values \pm standard error of the mean ( $n=3) ; P<0.05,{ }^{* *} P<0.01$, versus MCAO/R group; \# $P<0.05$, \#\# $P<0.01$ versus Shamoperated group.

\section{Methed}

\subsection{RSAE preparation}

Radix scrophulariae was purchased from Xinyi Town, Chun'an Town, Zhejiang Province in China; the aqueous extract of Radix scrophulariae (RSAE) was prepared by the Chinese Herbal Medicine Germplasm Resources and Evaluation Laboratory of Zhejiang University of Traditional Chinese Medicine, Hangzhou, in China. According to the experimental requirements, RSAE was prepared and diluted to different concentrations.

\subsection{Cell cultures and OGD/R models}

PC12 pheochromocytoma cells were obtained from the Institute of Basic Medical Sciences at the Chinese Academy of Medical Sciences [28], and were cultured at $37^{\circ} \mathrm{C}$ in Dulbecco's Modified 
Eagle's Medium (Gibico, U.S.) with 10\% fetal bovine serum (Gibico, U.S.), $100 \mathrm{U} / \mathrm{mL}$ penicillin and $100 \mathrm{mg} / \mathrm{mL}$ streptomycin in a normal incubator, which was used as a complete medium (CM) containing $4.5 \mathrm{~g} / \mathrm{L} \mathrm{D}$-glucose. $\mathrm{PC} 12$ cells with $1 \times 10^{5}$ cells $/ \mathrm{mL}$ of cell density, were seed in 96 -well plates in a volume of $100 \mu \mathrm{L}$ per well, and the cells were allowed to adhere and grow for $24 \mathrm{~h}$.

According to the oxygen glucose deprivation and reperfusion (OGD/R) model established in our lab [28, 29], we had made proper adjustments and replaced the growth medium with glucosefree DMEM (Gibico, U.S.) and put the plates into an anaerobic incubator under 95\% N2 and 5\% $\mathrm{CO} 2$ at $37^{\circ} \mathrm{C}$ for $120 \mathrm{~min}$. Then, after rapidly replacing by glucose-free DMEM with CM, cells were feed for a $24 \mathrm{~h}$ reperfusion period with a complete medium in a normal incubator. Control cell cultures were incubated under normal conditions and not deprived of oxygen and glucose. The cells were pretreated with different concentrations of RSAE, including $6.25 \mu \mathrm{g} / \mathrm{mL}, 12.5 \mu \mathrm{g} / \mathrm{mL}$, $25.0 \mu \mathrm{g} / \mathrm{mL}$ and $50.0 \mu \mathrm{g} / \mathrm{mL}$, and then were exposed to OGD/R injury.

\subsection{Cell viability analysis}

Cell viabilities of PC12 cells were assessed according to the MTT assay. After OGD/R, the 3-[4,5dimethylthiazol-2-yl]-2,5-diphenyltetrazolium bromide (MTT, Amresco, 0973) assay was used to detect cell viability, as previously described [28-30]. Briefly, MTT was dissolved in DMEM, and added to each well for incubation at a final concentration of $0.5 \mathrm{mg} / \mathrm{ml}$ at $37^{\circ} \mathrm{C}$ for $4 \mathrm{~h}$. Then, to dissolve the formazan crystals, $150 \mu$ l of DMSO was used to replace the medium per well for 10 min. An automatic Microplate Reader (Spectrauor, TECAN, Sunrise, Austria) was used to record the optical density (OD) of all groups at $570 \mathrm{~nm}$. Cell viability was expressed as a percentage of the control value. Each experiment was repeated quintuplicate using three independent cultures.

\subsection{Assessment of cell injury or death}

Cell viability analysis showed 12.5 of RSAE could improve OGD/R-induced PC12 Cell viability OGD/R-induced PC12 cells. To confirm the reliability of the MTT results, we used diagnostic kits to measure the amount of LDH release to assess cell injury or death. The four sets of experiments were carried out as follow: (1) control PC12 cells, (2) PC12 cells OGD/R induced, (3) PC12 cells pretreated with $12.5 \mu \mathrm{g} / \mathrm{mL}$ of RSAE for $24 \mathrm{~h}$, then induced by OGD/R, (4) control PC12 cells pretreated with $12.5 \mu \mathrm{g} / \mathrm{mL}$ of RSAE.

Based on the manufacturer's instructions, LDH release was determined via using an assay kit (Nanjing Jiancheng Bioengineering Institute, Nanjing, China). Culture media were harvested after $\mathrm{OGD} / \mathrm{R}$ injury to determine LDH levels. LDH leakage was expressed as the percentage of the total $\mathrm{LDH}$ activity (LDH in the medium + LDH in the cells).

\subsection{Determination of the levels of oxidative stress}

And After treatment, PC 12 cells induced by OGD/R were lysed using $0.2 \%$ Triton X-100 for $30 \mathrm{~min}$ to release intracellular superoxide malondialdehyde (MDA), dismutase (SOD), glutathione peroxidase (GSH-Px) and catalase (CAT). The levels of oxidative stress were determined by an automatic microplate reader (Spectrauor, TECAN, Sunrise, Austria), including MDA, SOD, GSH-Px and CAT, according to the kit instructions [31]. And a BCA Protein Assay Kit (Nanjing Jiancheng Bioengineering Institute, Nanjing, China) was used to detect the protein concentrations according to the manufacturer's instructions. The following four sets of experiments were performed: (1) control cells, (2) OGD/R induced PC 12 cells, (3) cells pretreated with $12.5 \mu \mathrm{g} / \mathrm{mL}$ of RSAE for $24 \mathrm{~h}$, then induced by OGD/R induced cells, (4) control cells pretreated with $12.5 \mu \mathrm{g} / \mathrm{mL}$ of RSAE.

\subsection{Measurement of mitochondrial membrane potential}

The change in mitochondrial membrane potential (MMP) was detected by JC-1 staining [31]. PC 12 
cells (cell density, $1 \times 10^{5}$ cells $/ \mathrm{mL}$ ) were cultured in 24 -well plates. After treatment, we harvested the cells and incubated them with JC-1 ( $2 \mathrm{mM}$ nal concentration) at $37^{\circ} \mathrm{C}$ in the dark for $30 \mathrm{~min}$. Then, the cells were immediately observed using a fluorescence microscopy (Leica, Germany Q9). The results were analyzed by the Image-Pro Plus6.0 [28]. The following four sets of experiments were performed: (1) control cells, (2) OGD/R induced PC 12 cells, (3) cells pretreated with $12.5 \mu \mathrm{g} / \mathrm{mL}$ of RSAE for $24 \mathrm{~h}$, then induced by OGD/R induced cells, (4) control cells pretreated with $12.5 \mu \mathrm{g} / \mathrm{mL}$ of RSAE.

\subsection{Mice MCAO/R model and drug administration}

Male Kunming (KM) mice (SPF, weighed 18-22g) by used in this study, were purchased from the Animal Experimental Center of Zhejiang University of Traditional Chinese Medicine. Mice were housed with an ambient temperature of $20 \pm 1^{\circ} \mathrm{C}$ and a 12 -hour light/dark cycle with free access to a standard laboratory chow diet and water. All subjects gave our informed consent for inclusion before we participated in the study. The study was conducted in accordance with the Declaration of Helsinki, and the protocol was approved by the Laboratory Animal Ethics Committee of the Institute of Medicinal Plant Development, Peking Union Medical College, and conformed to the Guide for the Care and Use of Laboratory Animals (Permit Number: SYXK 2017-0020).

For focal brain ischemia, the mouse middle cerebral artery occlusion and reperfusion model (MCAO/R) was used, as described previously [32-35]. In brief, animals were anesthetized with with Zoletil 50 at an intramuscular injection of $50 \mathrm{mg} / \mathrm{kg}$ (Virbac S.A, Carros, France) and maintained at half a dose. A silicone-coated 8-0 monofilament was used to introduce in the left internal carotid artery and advanced to occlude the middle cerebral artery for $2 \mathrm{~h}$. After $2 \mathrm{~h} \mathrm{MCAO}$, the animals were briefly re-anesthetized and the filament was withdrawn for reperfusion studies.

All animal were divided into 4 groups ( $n=10$ per group) according to the random number table, namely the MCAO/R operation model group, the sham operation group and the group of Radix scrophulariae aqueous extract (RSAE), which is equivalent to the original drug at a dose of $2.4 \mathrm{~g} \cdot \mathrm{kg}$ 1 , and the positive drug control group at a dose of $12 \mathrm{mg} \cdot \mathrm{kg}^{-1}$ nimodipine. Continuous gastric administration lasted for 7 days, once per day. The model group and the sham operation group were given an equal volume of physiological saline for injection.

\subsection{Quantification of infarct volume and brain water content}

After the MCAO/R operation, mice were anesthetized with Zoletil 50 at a Intramuscular injection of $50 \mathrm{mg} / \mathrm{kg}$ (Virbac S.A, Carros, France) and brains were removed and sectioned coronally at a thickness of $2 \mathrm{~mm}$, and then incubated in a phosphate buffer solution $(\mathrm{pH}=7.3)$ with $2 \%(\mathrm{w} / \mathrm{v}) 2,3,5$ triphenyltetrazolium chloride (TTC), and stained for $15 \mathrm{~min}$ at $37^{\circ} \mathrm{C}$ followed by overnight immersion [36]. The normal nor-ischemic tissue was stained red, while the infarct tissue area remained unstained (white). The infarct areas on each slice were quantified by using the Image J software. To compensate for the effect of brain edema, the corrected infarct volume was calculated as described previously (Ten male mice per group): corrected infarct area = left hemisphere area (right hemisphere area- infarct area) [37].

The mice were anesthetized and mouse brain tissue was acquired and processed as needed at $24 \mathrm{~h}$ after MCAO, and the 3-mm part of the ischemic hemisphere brain was cut from the anterior pole to detect the water content in the brain tissue. The wet-dry method was applied to determine brain water contents (BWC) in another subgroup ( $n=10$ per group). An electronic scale was used to weigh the ischemic and nor-ischemic hemispheres (wet weight). And after the ischemic brain hemispheres was dried overnight at $105^{\circ} \mathrm{C}$ in a desiccating oven, it was weighed again (dry weight), 
and the total brain water content was calculated according to: BWC \%= [(Wet weight - Dry weight $)$ ] Wet weight $] \times 100 \%[38,39]$.

3.8 Assessment of levels of superoxide dismutase, malondialdehyde and Nitric oxide At 24 hours after surgery, the animals were killed immediately, the brain was decapitated, and the right hemisphere was taken. The rest of the brain tissue was washed with pre-cooled saline, then the blood was removed and dried by filter paper. After being weighed, they were prepared as $10 \%$ brain tissue homogenate in a homogenizer, centrifuged at $3000 \mathrm{rpm} \cdot \mathrm{min}^{-1}$ for $10 \mathrm{~min}$, and the supernatant was taken and stored in a refrigerator at $-20^{\circ} \mathrm{C}$. The Brodford method was used to determine protein concentration from the collected supernatants. And the SOD activity was by xanthine oxidase, the MDA content was determined by thiobarbituric acid, and the Nitric oxide (NO) content was determined by nitrate reductase. All the determination were carried out by assay kits (Nanjing Jiancheng Bioengineering Institute, Nanjing, China) [40]. Ten male mice were used for each group.

\subsection{H\&E and Nissle staining}

After MCAO/R operation, the animals were anesthetized with Zoletil 50 and killed immediately. And then the animals were perfused through the heart with $4^{\circ} \mathrm{C}$ phosphate-buffered saline (PBS), followed by $4 \%$ paraformaldehyde. Finally, the intact brain was carefully removed and placed in brain buffer containing $4 \%$ formaldehyde fixative for hematoxylin and eosin staining (H\&E) staining, toluidine blue staining and other immunohistochemical staining.

Hematoxylin-eosin (H\&E) staining was used to revealed morphological features of injured neurons in the cerebral cortex and hippocampus. The samples were embedded in paraffin to cut for $5-\mu \mathrm{m}$ slices and $5-\mu \mathrm{m}$-thick serial coronal sections were generated and mounted on slides. The sections were stained using hematoxylin and eosin (H\&E) according to the described standard protocol $[34,41]$. The staining images were acquired using a light microscope (Leica DM4000B, Germany). Nissl staining was applied to observe morphologic changes in cells within the ischemic penumbra after MCAO/R operation, mainly containing CA1 in hippocampus [39]. After $24 \mathrm{~h}$ of $\mathrm{MCAO} / \mathrm{R}$ operation, the brains were processed as above, the samples were embedded in paraffin to cut for 5- $\mu \mathrm{m}$ slices and 5- $\mu \mathrm{m}$-thick serial coronal sections were generated and mounted on slides. After the $5-\mu \mathrm{m}$ thick sections were washed in cold water, the paraffin sections were stained with $1 \%$ toluidine blue for $20 \mathrm{~min}$, rinsed with PBS, dehydrated with graded alcohol, transparent with xylene, and fixed with neutral glue. An optical microscope was used to observe the section.

Normal neurons showed normal cell size, prominent protrusions, uniform cytoplasm, clear nuclear membrane, obvious nucleoli, and no chromatin condensation. Three high-magnitude $(10 \times 40)$ fibelds in the cortex and in the CA1 of hippocampal were randomly selected for image analysis, and the number of pyramidal cells was counted. The mean value was taken as the number of pyramidal cells in the sample ( $\mathrm{n}=10$ per group).

\subsection{Immunohistochemical evaluation}

After MCAO/R operation, the animals were anesthetized with Zoletil 50 and killed immediately. The tissue samples taken from mice were histologically processed and embedded in paraffin for immunohistochemical staining. Five micro slides were removed from these blocks and mounted on poly-L-lysine coated slides and immunohistochemically stained with $\mathrm{Bcl}-2$ and Bax primary antibodies, and then performed as described as previously reported with little modification [12, 16]. Finally, the slides were fixed with a water-based mounting medium and evaluated under an optical microscope. Three sections of ischemia brain tissue with 10×40 magnification (400 X) were 
randomly selected for image analysis via the Image J software.

\subsection{Western blot analysis}

Twenty-four hours after MCAO, ischemic brain sections that included the ischemic area and corresponding regions from the contralateral hemisphere were collected, and protein extracts were prepared as described previously [28, 31]. And the PVDF membrane (Millipore, USA) were blocked for $2 \mathrm{~h}$ in $5 \%$ nonfat milk in Tris-buffered saline (TBS)/Tween 20 and probed with the following antibodies: anti-BAX (1:200), anti-BCL-2 (1:200), anti-p-p38 (1:500), anti-p-38 (1:500), anti-p-ERK (1:200), anti-ERK (1:200), anti-cleaved caspase-3 (1:500), anti-p-JNK (1:200), anti-JNK (1:200), and anti- $\beta$-actin (1:1000). Protein expression was detected by an enhanced chemiluminescence method and imaged by using ChemiDoc XRS (Bio-Rad, USA). To eliminate the variations of protein expression, three independent experiments were performed to conform the changes in protein levels. Quantitative analyses were performed using the Gel-Pro analyzer software.

\subsection{Statistical analysis}

Data were presented as mean values \pm standard error of the mean. All analyses were performed using GraphPad Prism 7.0 statistical software (GraphPad Software, Inc., La Jolla, CA). One-way ANOVA was used to determine the differences between the groups and then post hoc LSD testing. Comparison of the two groups were performed by using the unpaired Student $t$ test. The $P$ Values $<0.05$ were considered to be significant. At least three independent experiments were performed for each experiment.

\section{Discussion}

It has been reported that in ischemic stroke, energy metabolism disorders and mitochondrial dysfunction, may lead to the formation of large amounts of free radicals, mediate oxidative damage to DNA, inhibit antioxidant enzyme activity, upregulate Bax level, downregulate Bcl-2 level in astrocytes, and finally suppress activation of Caspase-3 inducing neuronal apoptosis [42]. Our research found that RSAE could increase the antioxidant capacity of oxidative stress in OGD/Rinduced PC12 cells and MCAO/R model mice: the SOD, CAT and GSH-Px activities remarkably were improved (Figure 3 and Figure 5), meaning ROS may be reduced by inhibiting the production of ROS induced by MCAO/R, which leads to mitochondrial damage and induces mitochondrial apoptotic pathways. RASE can increase the reduction of ROS, thereby inhibiting the inhibition of apoptosis (Figure 1 and Figure 2). Therefore, the result showed that Pretreatment with RSAE (12.5 $\mu \mathrm{g} / \mathrm{mL}$ ) for $8 \mathrm{~h}$ and $16 \mathrm{~h}$ significantly improved the cell viability (Figure 1 ) and inhibited the OGD/Rinduced damage (Figure 2).

AS known, activation of cell suicide or apoptosis is induced by events such as growth factor deficiency, toxins, and glucose and oxygen deficiency. It has also been found that it can be controlled by a variety of regulators and regulatory proteins that have inhibitory (anti-apoptosis) effects on programmed cell death or block (pro-apoptosis) inhibitors. To prevent their target-cells from dying too soon, countering defensive apoptosis could be generated by encoding their own anti-apoptosis genes [43]. It is known that $\mathrm{BCl}-2$ and $\mathrm{Bax}$ are two major members of the $\mathrm{Bcl}-2$ family, and the Bcl-2 family primarily regulates cell apoptosis and necrosis.

As a sensor of cell damage and stimulation, Bax is generally located in the cytoplasm. When cells are damaged and stimulated, Bax can form pores across the mitochondrial outer membrane, leading to a decrease in MMP and an outflow of $\mathrm{Cyt} C$ and other apoptosis-inducing factors. It also 
activates Caspase-3 and destroys the anti-apoptotic function of the $\mathrm{Bcl}-2$ proein under normal conditions [44]. And the anti-apoptotic protein Bcl-2 is an important intracellular component that inhibits the overexpression of Bax by blocking Cyt $\mathrm{C}$ release from mitochondria and Caspase- 3 aggregation, and links the mitochondrial outer membrane to stabilize membrane permeability and protect. Mitochondrial integrity, which in turn inhibits apoptosis [44], which both play an important regulatory role in the mitochondrial pathway. Therefore, the ratio of $\mathrm{Bax} / \mathrm{Bcl}-2$ is considered to be an important indicator related to apoptosis.

In this study, we used immunohistochemistry to detect changes in the expression of Bax and Bcl-2. It was suggested that RSAE producing anti-apoptotic protection effects on ischemia stroke was involved in upregulating Bcl-2 protein and downregulating Bax protein expression (Figure 4 and 6). So, we speculated RSAE, thereby exerting anti-apoptotic effect, may inhibit the activation of Caspase- 3 by regulating the expression of the Bcl-2 and Bax. At the same time, RSAE pretreatment increased the antioxidant activity, the mitochondrial membrane potential was stabilized, indicating that it may exert a protective effect by regulating the oxidative stress and activation of cell suicide or apoptosis pathway [8-10, 13, 18, 27, 42].

During ischemic stroke, as known, cerebral $\mathrm{I} / \mathrm{R}$ after cerebral infarction can cause neuronal apoptosis, and reaches the summit 1 to 5 days after ischemia, and can last for about 4 weeks [4, $14,40,45]$. And study revealed that apoptosis was a dynamic progressive process after cerebral ischemia-reperfusion. At the early stage of $30 \mathrm{~min}$, edema appeared in the anterior synovial striatum ischemic area, around the edema area. A minor number of apoptotic cells appeared, and with the prolongation of reperfusion time $(6-72 \mathrm{~h})$, the number of apoptotic cells increased, and they were mainly located in the penumbra of the brain slices. The CA1 area of the hippocampus is considered to be sensitive to ischemic injury. For example, ischemia-induced damage cannot be corrected and suppressed in time, and the penumbra will inevitably deteriorate and become part of a permanent infarct [45]. In the central area of cerebral ischemia, the cells mainly existed in the form of necrosis, and the cell death around the ischemic area was mainly apoptosis. As for the form of neuronal death caused by ischemic injury, it depends on the severity of the injury, the different mechanisms of occurrence and the length of the ischemic time, the number of apoptotic cells, the location, and the time and extent of ischemia. Therefore, the mechanism of timely and effective inhibition of neuronal apoptosis during cerebral ischemia is not fully understood, but a large number of studies have shown that neuronal apoptosis is related to cell cycle regulation [8-10, 13, $18,27,42]$.

Nissle staining and H\&E staining showed that the number of positive cells in the ischemic (MCAO/R) group was significantly higher than that in the sham-operated group, and the number of neuron-positive cells was significantly decreased, while the number of apoptosis-positive cells in the RSAE-treated group was significantly lower than that in the MCAO/R group, the number of positive cells increased, and the infarct size of the intervention group was significantly smaller than that of the ischemic group (Figure 7). Western blot analysis showed MCAO/R made the phosphorylation levels of ERK1/2 and p38 MAPK protein significantly increase in the ischemic penumbra (Figure 8). However, the increasement of the phosphorylation levels of ERK1/2 and p38 induced by MCAO/R was strikingly abrogated by pretreatment with RSAE, which indicated RSAE may modulate the ERK1/2 and p-38 MAPK Pathway via phosphorylation levels in MCAO/R mice. In addition, RSAE had no effect on the ERK1/2, p-JNK1/2, JNK1/2 and p38 expression (Figure 8), indicating that the RSAE may regulate cytokine expression and suppress cell apoptosis after stroke 
via at least partly modulating MAPK signaling pathway. However, it is not yet determined Whether RSAE binds directly to membrane receptors or regulates MAKP through a certain type of signal. And specific single active ingredients have not been determined, which needs to be further explored in depth.

\section{Conclusion}

In summary, our researches initially proved that Radix scrophulariae aqueous extract (RSAE) exerting a neuroprotective effects on cerebral ischemia and reperfusion (I/R) injury in oxygen glucose deprivation and reperfusion (OGD/R)-induced PC12 cells and middle cerebral artery occlusion/reperfusion (MCAO/R) model mice, were associated with attenuation of infarct volume, brain water content, nitric oxide (NO) and malondialdehyde (MDA), inhibiting I/R-induced damage by reducing the levels of LDH release, improving anti-oxidant capacity by upregulating the SOD, GSH-Px and CAT activity, stabilizing mitochondrial membrane potential, reducing neuronal apoptosis, necrosis and neuronal loss by regulating the expression of anti-apoptotic BCL-2and proapoptotic protein Bax, and elucidating downregulate the phosphorylation levels of MAPK pathways. Our findings may elaborate the neuroprotective effects and potential mechanisms of RSAE on focal cerebral I/R injury in mice.

Since, Radix scrophulariae, as a potential neuroprotective natural plant, has originally been identified to, our results may offer directions and clues for discovering new active compounds or drugs for treatment of ischemic stroke, which allows us to discover many new natural active chemicals by chemical separation and identification, and provide new insights into therapeutic targets in stroke patients.

Acknowledgments: This work was supported by the Major Scientific and Technological Special Project for the Special Research Project for TCM (No. 201507004), the National Natural Science Foundation of China (No. 81503290) and the National Natural Science Foundation of China (NO. 81773938).

Author Contributions: W.X., P.Z., C.Z. and X.Z. designed and performed the research; W.X. and P.Z. wrote the manuscript; X.Z. and P.Z. performed the statistical analysis; and C.Z. helped map the figures and revise the manuscript. X. S. and G. S. supervised the experiments and revised the manuscript.

Conflicts of Interest: The authors declare no conflicts of interest.

\section{References}

1. Wardlaw, J.M., G. Zoppo, T. Yamaguchi, and E. Berge, Thrombolysis for acute ischaemic stroke. Cochrane Database Syst Rev, 2003(3): p. Cd000213.

2. Eltzschig, H.K. and T. Eckle, Ischemia and reperfusion--from mechanism to translation. Nat Med, 2011. 17(11): p. 1391-401.

3. Turley, K.R., L.H. Toledo-Pereyra, and R.U. Kothari, Molecular mechanisms in the pathogenesis and treatment of acute ischemic stroke. J Invest Surg, 2005. 18(4): p. 207-18.

4. Bereczki, D., [Pharmacotherapy of stroke]. Neuropsychopharmacol Hung, 2009. 11(1): p. 7-13.

5. Ischaemic stroke: acute-phase drug therapy. Mostly aspirin and heparin. Prescrire Int, 2005. 14(78): p. 146-52. 
6. del Zoppo, G.J., J.L. Saver, E.C. Jauch, and H.P. Adams, Expansion of the Time Window for Treatment of Acute Ischemic Stroke With Intravenous Tissue Plasminogen Activator: A Science Advisory From the American Heart Association/American Stroke Association. Stroke; a journal of cerebral circulation, 2009. 40(8): p. 2945-2948.

7. Sandercock, P., J.M. Wardlaw, R.I. Lindley, M. Dennis, G. Cohen, G. Murray, K. Innes, G. Venables, A. Czlonkowska, A. Kobayashi, S. Ricci, V. Murray, E. Berge, K.B. Slot, G.J. Hankey, M. Correia, A. Peeters, K. Matz, P. Lyrer, G. Gubitz, S.J. Phillips, and A. Arauz, The benefits and harms of intravenous thrombolysis with recombinant tissue plasminogen activator within $6 \mathrm{~h}$ of acute ischaemic stroke (the third international stroke trial [IST-3]): a randomised controlled trial. Lancet, 2012. 379(9834): p. 2352-63.

8. Chen, C.H., S.J. Chen, C.C. Su, C.C. Yen, T.J. Tseng, T.R. Jinn, F.C. Tang, K.L. Chen, Y.C. Su, I. Lee k, D.Z. Hung, and C.F. Huang, Chloroacetic acid induced neuronal cells death through oxidative stress-mediated p38-MAPK activation pathway regulated mitochondria-dependent apoptotic signals. Toxicology, 2013. 303: p. 72-82.

9. Lu, T.H., S.Y. Hsieh, C.C. Yen, H.C. Wu, K.L. Chen, D.Z. Hung, C.H. Chen, C.C. Wu, Y.C. Su, Y.W. Chen, S.H. Liu, and C.F. Huang, Involvement of oxidative stress-mediated ERK1/2 and p38 activation regulated mitochondria-dependent apoptotic signals in methylmercury-induced neuronal cell injury. Toxicol Lett, 2011. 204(1): p. 71-80.

10. Lu, T.H., T.J. Tseng, C.C. Su, F.C. Tang, C.C. Yen, Y.Y. Liu, C.Y. Yang, C.C. Wu, K.L. Chen, D.Z. Hung, and Y.W. Chen, Arsenic induces reactive oxygen species-caused neuronal cell apoptosis through JNK/ERK-mediated mitochondria-dependent and GRP 78/CHOP-regulated pathways. Toxicol Lett, 2014. 224(1): p. 130-40.

11. Lu, T.-H., S.-Y. Hsieh, C.-C. Yen, H.-C. Wu, K.-L. Chen, D.-Z. Hung, C.-H. Chen, C.-C. Wu, Y.-C. Su, Y.W. Chen, S.-H. Liu, and C.-F. Huang, Involvement of oxidative stress-mediated ERK1/2 and p38 activation regulated mitochondria-dependent apoptotic signals in methylmercury-induced neuronal cell injury. Toxicology Letters, 2011. 204(1): p. 71-80.

12. Ma, D., N. Wang, X. Fan, L. Zhang, Y. Luo, R. Huang, L. Zhang, Y. Li, G. Zhao, and L. Li, Protective Effects of Cornel Iridoid Glycoside in Rats After Traumatic Brain Injury. Neurochem Res, 2018. 43(4): p. 959-971.

13. Pietri, M., A. Caprini, S. Mouillet-Richard, E. Pradines, M. Ermonval, J. Grassi, O. Kellermann, and B. Schneider, Overstimulation of PrPC signaling pathways by prion peptide 106-126 causes oxidative injury of bioaminergic neuronal cells. J Biol Chem, 2006. 281(38): p. 28470-9.

14. Khoshnam, S.E., W. Winlow, M. Farzaneh, Y. Farbood, and H.F. Moghaddam, Pathogenic mechanisms following ischemic stroke. Neurological Sciences, 2017. 38(7): p. 1167-1186.

15. Liu, X., W. Tan, F. Yang, Y. Wang, S. Yue, T. Wang, and X. Wang, Shengmai injection reduces apoptosis and enhances angiogenesis after myocardial ischaemia and reperfusion injury in rats. Biomed Pharmacother, 2018. 104: p. 629-636.

16. Sezen, S.C., A. Kucuk, A. Ozer, Y. Kilic, B. Mardin, M. Alkan, F.D. Erkent, M. Arslan, Y. Unal, G.L. Oktar, and M. Tosun, Assessment of the effects of levosimendan and thymoquinone on lung injury after myocardial ischemia reperfusion in rats. Drug Des Devel Ther, 2018. 12: p. 13471352.

17. Xue, R., Q. Meng, D. Lu, X. Liu, Y. Wang, and J. Hao, Mitofusin2 Induces Cell Autophagy of Pancreatic Cancer through Inhibiting the PI3K/Akt/mTOR Signaling Pathway. Oxid Med Cell Longev, 2018. 2018: p. 2798070. 
18. Sun, J. and G. Nan, The Mitogen-Activated Protein Kinase (MAPK) Signaling Pathway as a Discovery Target in Stroke. J Mol Neurosci, 2016. 59(1): p. 90-8.

19. Yang, C.H., T.L. Yen, C.Y. Hsu, P.A. Thomas, J.R. Sheu, and T. Jayakumar, Multi-Targeting Andrographolide, a Novel NF-kappaB Inhibitor, as a Potential Therapeutic Agent for Stroke. Int J Mol Sci, 2017. 18(8).

20. Lebesgue, D., V. Chevaleyre, R.S. Zukin, and A.M. Etgen, Estradiol rescues neurons from global ischemia-induced cell death: multiple cellular pathways of neuroprotection. Steroids, 2009. 74(7): p. 555-61.

21. Sun, K., J. Fan, and J. Han, Ameliorating effects of traditional Chinese medicine preparation, Chinese materia medica and active compounds on ischemia/reperfusion-induced cerebral microcirculatory disturbances and neuron damage. Acta Pharm Sin B, 2015. 5(1): p. 8-24.

22. Wang, J.Z., F. Xu, Z. Liu, L.M. Ma, M.Y. Shang, G.X. Liu, and S.Q. Cai, [Identification of chemical constituents in Scrophulariae Radix by HPLC-IT-TOF-MS]. Zhongguo Zhong Yao Za Zhi, 2016. 41(7): p. 1257-1268.

23. You-Hua, C., Q.I. Jin, H.U.A. Jing, and Y.U. Bo-Yang, Structural characterization and identification of major constituents in Radix scrophulariae by HPLC coupled with electrospray ionization quadrupole time-of-flight tandem mass spectrometry. Chinese Journal of Natural Medicines, 2014. 12(1): p. 47-54.

24. Shen, X., T. Eichhorn, H.J. Greten, and T. Efferth, Effects of Scrophularia ningpoensis Hemsl. on Inhibition of Proliferation, Apoptosis Induction and NF-kappaB Signaling of Immortalized and Cancer Cell Lines. Pharmaceuticals (Basel), 2012. 5(2): p. 189-208.

25. Chang, K.C., C.C. Hsu, S.H. Liu, C.C. Su, C.C. Yen, M.J. Lee, K.L. Chen, T.J. Ho, D.Z. Hung, C.C. Wu, T.H. Lu, Y.C. Su, Y.W. Chen, and C.F. Huang, Cadmium induces apoptosis in pancreatic beta-cells through a mitochondria-dependent pathway: the role of oxidative stress-mediated c-Jun $\mathrm{N}$ terminal kinase activation. PLoS One, 2013. 8(2): p. e54374.

26. Lee, K.I., C.C. Su, C.Y. Yang, D.Z. Hung, C.T. Lin, T.H. Lu, S.H. Liu, and C.F. Huang, Etoposide induces pancreatic beta-cells cytotoxicity via the JNK/ERK/GSK-3 signaling-mediated mitochondriadependent apoptosis pathway. Toxicol In Vitro, 2016. 36: p. 142-152.

27. Yu, J., M. Eto, K. Kozaki, M. Akishita, T. Okabe, and Y. Ouchi, Raloxifene analogue LY117018 suppresses oxidative stress-induced endothelial cell apoptosis through activation of ERK1/2 signaling pathway. Eur J Pharmacol, 2008. 589(1-3): p. 32-6.

28. Ma, B., X. Meng, J. Wang, J. Sun, X. Ren, M. Qin, J. Sun, G. Sun, and X. Sun, Notoginsenoside R1 attenuates amyloid-6-induced damage in neurons by inhibiting reactive oxygen species and modulating MAPK activation. International immunopharmacology, 2014. 22(1): p. 151-159.

29. Zhou, P., S. Lu, Y. Luo, S. Wang, K. Yang, Y. Zhai, G. Sun, and X. Sun, Attenuation of TNF- $\alpha$-Induced Inflammatory Injury in Endothelial Cells by Ginsenoside Rb1 via Inhibiting NF-KB, JNK and p38 Signaling Pathways. Frontiers in Pharmacology, 2017. 8(464).

30. Wang, S., M. Wang, M. Wang, Y. Tian, X. Sun, G. Sun, and X. Sun, Bavachinin Induces Oxidative Damage in HepaRG Cells through p38/JNK MAPK Pathways. Toxins, 2018. 10(4): p. 154.

31. Ai, Q., G.-B. Sun, Y. Luo, X. Dong, H. Ruifeng, X. Meng, and X. Sun, Ginsenoside Rb1 prevents hypoxia-reoxygenation-induced apoptosis in H9c2 cardiomyocytes via an estrogen receptordependent crosstalk among the AKt, JNK, and ERK 1/2 pathways using a label-free quantitative proteomics analysis. Vol. 5. 2015.

32. Wang, M., X. Xu, H. Xu, F. Wen, X. Zhang, H. Sun, F. Yao, G. Sun, and X. Sun, Effect of the total 
saponins of Aralia elata (Miq) Seem on cardiac contractile function and intracellular calcium cycling regulation. J Ethnopharmacol, 2014. 155(1): p. 240-7.

33. Gao, F., G. Sun, X. Ren, Y. Nie, J. Sun, M. Qin, and X. Sun, [Protective effect of salvianolic acid $B$ on isolated heart ischemia/reperfusion injury in rats]. Zhongguo Zhong Yao Za Zhi, 2012. 37(3): p. 358-61.

34. Di, Y., Y.-L. He, T. Zhao, X. Huang, K.-W. Wu, S.-H. Liu, Y.-Q. Zhao, M. Fan, L.-Y. Wu, and L.-L. Zhu, Methylene Blue Reduces Acute Cerebral Ischemic Injury via the Induction of Mitophagy. Vol. 21. 2015.

35. Qiu, J., M. Nishimura, Y. Wang, J. R Sims, S. Qiu, S. I Savitz, S. Salomone, and M. Moskowitz, Early release of HMGB-1 from neurons after the onset of brain ischemia. Vol. 28. 2008. 927-38.

36. Jin, Z., J. Liang, J. Wang, and P.E. Kolattukudy, MCP-induced protein 1 mediates the minocyclineinduced neuroprotection against cerebral ischemia/reperfusion injury in vitro and in vivo. Journal of Neuroinflammation, 2015. 12(1): p. 39.

37. Lin, T.-n., Y. He, G. Wu, M. Khan, and C. Hsu, Lin TN, Yong YH, Wa G, Khan M \& Hsu CY.Effect of brain edema on infarct volume in a focal ischemia model in rats. Stroke 24: 117-121. Vol. 24. 1993. 117-21.

38. Chen, W., B. Xu, A. Xiao, L. Liu, X. Fang, R. Liu, E. Turlova, A. Barszczyk, X. Zhong, C.L. Sun, L.R. Britto, Z.P. Feng, and H.S. Sun, TRPM7 inhibitor carvacrol protects brain from neonatal hypoxicischemic injury. Mol Brain, 2015. 8: p. 11.

39. Ma, Y.L., Q. Pei, L. Yan, S. Lan, S.Q. Wang, H.L. Dong, W.G. Hou, and L.Z. Xiong, The effects of different doses of estradiol (E2) on cerebral ischemia in an in vitro model of oxygen and glucose deprivation and reperfusion and in a rat model of middle carotid artery occlusion. Bmc Neuroscience, 2013. 14(1): p. 1-15.

40. Jiang, M., J. Li, Q. Peng, Y. Liu, W. Liu, C. Luo, J. Peng, J. Li, K.K.L. Yung, and Z. Mo, Neuroprotective effects of bilobalide on cerebral ischemia and reperfusion injury are associated with inhibition of pro-inflammatory mediator production and down-regulation of JNK1/2 and p38 MAPK activation. Journal of Neuroinflammation, 2014. 11(1): p. 167.

41. Tao, X., X. Sun, L. Yin, X. Han, L. Xu, Y. Qi, Y. Xu, H. Li, Y. Lin, and K. Liu, Dioscin ameliorates cerebral ischemia/reperfusion injury through the downregulation of TLR4 signaling via HMGB1 inhibition. Free Radical Biology \& Medicine, 2015. 84: p. 103-115.

42. Procaccio, V., C. Bris, J.M. Chao de la Barca, F. Oca, A. Chevrollier, P. Amati-Bonneau, D. Bonneau, and P. Reynier, Perspectives of drug-based neuroprotection targeting mitochondria. Revue Neurologique, 2014. 170(5): p. 390-400.

43. Vaux, D.L., A boom time for necrobiology. Current Biology, 1993. 3(12): p. 877-878.

44. Martinou, J.-C. and Richard J. Youle, Mitochondria in Apoptosis: BCl-2 Family Members and Mitochondrial Dynamics. Developmental Cell, 2011. 21(1): p. 92-101.

45. Martin-Romero, F.J., B. Santiago-Josefat, J. Correa-Bordes, C. Gutierrez-Merino, and P. Fernandez-Salguero, Potassium-induced apoptosis in rat cerebellar granule cells involves cellcycle blockade at the G1/S transition. J Mol Neurosci, 2000. 15(3): p. 155-65. 